\title{
Article \\ Electromagnetic Shielding Effectiveness of Glass Fiber/Epoxy Laminated Composites with Multi-Scale Reinforcements
}

\author{
Nilufar Yesmin ${ }^{1}$ and Vijaya Chalivendra ${ }^{2, *(D)}$ \\ 1 Department of Physics, University of Massachusetts, North Dartmouth, MA 02747, USA; \\ nyesmin@umassd.edu \\ 2 Department of Mechanical Engineering, University of Massachusetts, North Dartmouth, MA 02747, USA \\ * Correspondence: vchalivendra@umassd.edu; Tel.: +1-508-910-6572
}

Citation: Yesmin, N.; Chalivendra, V. Electromagnetic Shielding Effectiveness of Glass Fiber/Epoxy Laminated Composites with Multi-Scale Reinforcements. J. Compos. Sci. 2021, 5, 204. https:// doi.org/10.3390/jcs5080204

Academic Editors: Xiangfa Wu and Francesco Tornabene

Received: 25 June 2021

Accepted: 30 July 2021

Published: 3 August 2021

Publisher's Note: MDPI stays neutral with regard to jurisdictional claims in published maps and institutional affiliations.

Copyright: (c) 2021 by the authors. Licensee MDPI, Basel, Switzerland. This article is an open access article distributed under the terms and conditions of the Creative Commons Attribution (CC BY) license (https:/ / creativecommons.org/licenses/by/ $4.0 /)$.

\begin{abstract}
In this study, an experimental investigation has been performed to understand the electromagnetic interference-shielding effectiveness (EMI-SE) of glass fiber/epoxy laminated composites embedded with carbon nanotubes (CNTs) and $\mathrm{Fe}_{3} \mathrm{O}_{4}$ nanoparticles, reinforced with micro carbon fibers along the thickness direction. Micro carbon fibers were reinforced along the thickness direction between the laminates using an electro-flocking process and a vacuum infusion process used to fabricate the composites. The EMI-SE of the composites was measured in the X-band frequency range $(8-12 \mathrm{GHz})$. The effect of carbon fibers of three different lengths $(80 \mu \mathrm{m}, 150 \mu \mathrm{m}$, and $350 \mu \mathrm{m})$ with two different fiber densities (1000 and 2000 fibers $/ \mathrm{mm}^{2}$ ) and two different amounts of $\mathrm{Fe}_{3} \mathrm{O}_{4}$ nanoparticles ( 0.5 and $1 \mathrm{wt} . \%$ ) on total SE, absorption, and reflection was investigated. Due to the synergetic effect of $\mathrm{Fe}_{3} \mathrm{O}_{4}$ nanoparticles, CNTs, and carbon fibers, the final EMI shielding of the composites was mainly dominated by the absorption process. The absorption was more pronounced in the composites of longer carbon fibers with improved electrical conductivity. The presence of $\mathrm{Fe}_{3} \mathrm{O}_{4}$ nanoparticles also enhanced total SE values with improved magnetic permeability. The composite with micro carbon fibers of $350 \mu \mathrm{m}$ length and 2000 fibers $/ \mathrm{mm}^{2}$ density with $1 \mathrm{wt} . \%$ of $\mathrm{Fe}_{3} \mathrm{O}_{4}$ nanoparticles showed the maximum value of total SE.
\end{abstract}

Keywords: electromagnetic shielding; glass/epoxy composites; carbon nanotubes; carbon fibers; iron oxide nanoparticles; electro flocking

\section{Introduction}

Electromagnetic shielding (EMS) is often used to cut down emissions or enhance the protection of electronic equipment. In the past, enclosures of electronic equipment were produced using highly conducting metal to accomplish the required shielding. However, design constraints called for reducing the weight of electronic devices with conducting polymers and composites [1-4]. There have been several studies on the use of polymer composites to enhance EMS for the last decade. Researchers investigated the effects of various reinforcements on the EMS of the polymer composites. Jou et al. [5] investigated the electromagnetic shielding effectiveness (SE) of carbon nanotubes (CNTs) embedded polymers. The authors studied the use of CNTs of two different aspect ratios of 500 and 10,000 in liquid crystal polymers (LCPs) and melamine resins (MF). It was identified in their study that at a higher aspect ratio, a greater SE value was observed. Park et al. [6] reported the use of both single-walled and multi-walled CNTs functionalized with the epoxy linkage of the RET polymer on EMS. Through functionalization, they achieved good dispersion of CNTs in the polymer matrix and single-walled CNTs embedded composites showed superior EMS compared to those of multi-walled nanocomposites. Jalali et al. [7] improved the EM shielding especially absorption component of carbon fiber reinforced polymer composites filled with metallic nanoparticles of iron, cobalt, nickel, and iron oxide at higher frequency. The iron nanoparticles of $50 \mathrm{~nm}$ improved the total shielding effectiveness of a carbon fibre/polymer nanocomposite up to $15 \mathrm{~dB}$ in the $8.2-12.4 \mathrm{GHz}$ range frequency. 
Joshi et al. [8] studied graphene nanoribbon (GNR)/Polyaniline (PANI)/epoxy composite film for effective shielding material in the X-band frequency range of 8.2-12.4 GHz. The authors examined the effect of the GNR percentage and the thickness of the film on the shielding effectiveness. Their composites show $-40 \mathrm{~dB}$ shielding which is sufficient to shield more than $95 \%$ of the EM waves in the X Band. Using chemical vapor infiltration, Jia et al. [9] fabricated carbon fiber-reinforced multilayered pyrocarbon-silicon carbide ((PyC-SiC)n) matrix (C/(PyC-SiC)n) composites by means of layer-by-layer deposition of PyC and SiC. The influence of the number of PyC-SiC sequences $(\mathrm{n}=1,2$ and 4$)$ on the electrical conductivity and EMI shielding performance of $\mathrm{C} /(\mathrm{PyC}-\mathrm{SiC}) \mathrm{n}$ composites were determined. The total SE of the composites increased from 34 to $42 \mathrm{~dB}$ in the frequency range of $8.2-12.4 \mathrm{GHz}$ with the increase of PyC-SiC sequences number due to the improvement of electrical conductivity and polarization of the multilayered matrix. Saini and Choudhary [10] fabricated non-covalently functionalized (polyaniline coated) MWCNTs/polystyrene composites with an extremely low percolation threshold ( $0.12 \mathrm{vol} . \%$ MWCNT) using a solution processing route. In their electromagnetic interference studies, due to high conductivity and porosity, these composites exhibited shielding effectiveness of $-23.3 \mathrm{~dB}$. This shielding is dominated by absorption $(-18.7 \mathrm{~dB})$ with a marginal contribution from reflection $(-4.6 \mathrm{~dB})$. Hu et al. [11] recently reinforced Polyvinylpyrrolidone (PVP) functionalized CNTs and KH-550 silane coupling agent treated $\mathrm{Fe}_{3} \mathrm{O}_{4}$ in lignin-based polyurethane for EMI shielding effectiveness measurements. They reported excellent EMI SE values and they were attributed to the synergistic effects between $\mathrm{Fe}_{3} \mathrm{O}_{4}, \mathrm{CNT}$ and lignin. Shuba et al. [12] investigated the electromagnetic response of a composite material consisting of single-walled carbon-nanotubes in a wide range from low-frequency $\left(25-10^{7} \mathrm{~Hz}\right)$ up to the infrared region. They reported that the real part of the permittivity of the p-CNT film in the terahertz range is competitive.

Besides adding nanoparticles and short fibers in polymers, researchers also investigated the use of embedding nanoparticles in laminated composites for electromagnetic shielding applications. Chen et al. [13] used copper wire and polyamide filaments as core yarn and later wrapped with polypropylene filaments. They utilized identical yarn for both warp and weft to realize isotropic shielding behavior. Plane-wave shielding properties (SE) of isotropic fabrics and laminated composites were determined at $30-1500 \mathrm{MHz}$ using the coaxial transmission-line method. In their findings, the shielding effectiveness of a single layer was not satisfactory for conventional applications and the multi-layer fabrics deliver sufficient plane-wave shielding effectiveness $(20-55 \mathrm{~dB})$ when the wave was normally incident and composite thickness was more than $1.6 \mathrm{~mm}$. Huang et al. [14] used copper wires, stainless-steel (SS) wires, and polyester (PET) filaments to make copper/PET, $\mathrm{SS} / \mathrm{PET}$, and copper/SS/PET composite ply yarns. Later authors knitted these ply yarns into electromagnetic shielding fabrics with various knitting-needle densities. Their findings indicated that the copper/SS/PET fabrics demonstrated an SE value of $10 \mathrm{~dB}$, greater than that of the copper/PET or SS/PET fabrics. Tugirumubano et al. [15] recently evaluated electromagnetic interference shielding of bimetal (stainless steel-copper, stainless steel-nickel, and copper-nickel)/carbon prepreg fibers textile composite materials. A combination of stainless steel-copper-carbon fiber with a shielding effectiveness of $131.6 \mathrm{~dB}$ was found to be the best for electromagnetic interference shielding. Very recently, Rojas et al. [16] studied electromagnetic shielding effectiveness of serrated and rectangular strips of highly porous carbon nanotube buckypaper (BP) incorporated glass fiber/epoxy resin composites. About $90 \%$ of attenuation $(8.2-10.8 \mathrm{GHz})$ was achieved for laminates containing between 0.75 and $2.5 \mathrm{wt} . \%$ CNTs. Greater attenuation values of $-41.04 \mathrm{~dB}(>99.99 \%)$ at $8.3 \mathrm{GHz}$ were achieved in the reflectivity analysis for laminates with serrated strips at 0.75 wt. $\%$ of CNTs.

Although there are many studies reported on electromagnetic shielding effectiveness of laminated composites with several metal/textile weaves and reinforcements, there are no studies reported in the literature on the reinforcing of micro carbon fibers (CF) between the laminates along the thickness direction, in addition to CNTs and $\mathrm{Fe}_{3} \mathrm{O}_{4}$ nanoparticles in 
glass fiber/epoxy composites on EMS effectiveness. The through thickness reinforcement of micro carbon fibers generates a three-dimensional electrically conductive network inside the composites. These micro CF can penetrate through the laminates and help to make contact with CNTs in the matrix and micro CF of the neighboring plies [17]. Hence, in this study, novel laminated composites were made by reinforcing micro carbon fibers of three different lengths and two different fiber densities along the thickness direction while embedding CNTs and two different weight percentages of $\mathrm{Fe}_{3} \mathrm{O}_{4}$ nanoparticles. The effect of above parameters on total SE, absorption SE, and reflection SE in X-band frequency $(8-12 \mathrm{GHz})$ is investigated.

\section{Materials and Methods}

\subsection{Materials}

Glass fabric of $10 \mathrm{oz} / \mathrm{yd}^{2}$ supplied by Fibre Glast Development Corporation, Brookville, $\mathrm{OH}, \mathrm{USA}$ is used as laminate. Thermoset epoxy of system 2000 resin and 2120 hardener supplied by the same company was used as the matrix. Multi-walled carbon nanotubes (MWCNTs) having an external diameter of 20-30 nm, internal diameter of 5-10 nm, length of 10-30 $\mu \mathrm{m}$, and purity greater than $95 \%$ was supplied by Cheap Tubes Inc., Cambridgeport, VT, USA. In this study, three types of carbon fibers were used. Carbon fibers of length of $80 \mu \mathrm{m}$ and $150 \mu \mathrm{m}$ with a diameter of 7-9 $\mu \mathrm{m}$ were supplied by Asbury Graphite Mills, Bloomsbury, NJ, USA. Carbon fibers of length of $350 \mu \mathrm{m}$ and $7 \mu \mathrm{m}$ diameter were supplied by E\&L Enterprises, Galliano, LA, USA. All fibers consist of $99 \%$ carbon content and a mass density of $1.8 \mathrm{~g} / \mathrm{cc}$. $\mathrm{Fe}_{3} \mathrm{O}_{4}$ nano particles of $20 \mathrm{~nm}$ (>99.5\% purity) were supplied by US Research Nanomaterials, Inc. All lab supplies used for vacuum infusion were procured from Fibre Glast Development Corporation, Brookville, OH, USA.

\subsection{Dispersion of $\mathrm{CNTs}$ and $\mathrm{Fe}_{3} \mathrm{O}_{4}$ Nano Particles}

Due to the high surface area of MWCNTs and clustering $\mathrm{Fe}_{3} \mathrm{O}_{4}$ nano particles, they were dispersed properly in the epoxy matrix while making the composites [18]. Based on previous study, for all composite types, $0.3 \mathrm{wt} . \%$ of CNTs was used [17]. First, a measured amount of CNTs was hand mixed in the epoxy resin for 10 minutes. Then the mix was placed in an ice bath and a combination of shear mixing and an ultrasonication process was performed for 60 minutes. The shear mixture (IKA model number RW 16 basic overhead stirrer) was set at $600 \mathrm{rpm}$. Ultrasonicator (Cole-Parmer model CP 750) was set to pulse cycle of 4 seconds on and 9 seconds off. To prevent the generation of excessive heat during the sonication process, the mix was always placed in an ice bath and maintained at room temperature. After 60 minutes, the mix was placed into a vacuum chamber for 60 minutes to remove the entrapped air bubbles. After de-gassing, the measured amount of hardener of the epoxy was added into the mix and hand mixed for 10 minutes. Then, the whole mix was placed again in the vacuum chamber for additional de-gassing. For the composites with $\mathrm{Fe}_{3} \mathrm{O}_{4}$ nano particles ( 0.5 and 1 wt.\%), the measured powder was added, and ultra-sonicated \& shear mixed for another 60 minutes after mixing of CNTs.

\subsection{Electro-Flocking of Micro Carbon Fibers}

Micro carbon fibers of three different lengths $(80 \mu \mathrm{m}, 150 \mu \mathrm{m}$, and $350 \mu \mathrm{m})$ were reinforced on the laminates along the thickness direction using an electro-flocking process [19]. Figure 1 shows the electro-flocking set up, where carbon fibers were uniformly spread on the bottom plate (electrode) and glass fabric coated using a paint brush with epoxy embedded with $\mathrm{CNTs}$ (CNTs and $\mathrm{Fe}_{3} \mathrm{O}_{4}$ nano particles) was attached to the top plate (electrode). A high electrical potential of $30-80 \mathrm{kV}$ was applied between the electrodes. The potential difference drove the carbon fibers from the bottom plate to top plate and embed into the glass fabric. This process was repeated for 9 layers to make a laminated composite with 10 layers, where the top layer was not flocked. The carbon fiber lengths and fiber densities of 1000 and 2000 fibers $/ \mathrm{mm}^{2}$ were chosen based on our previous study [17]. 


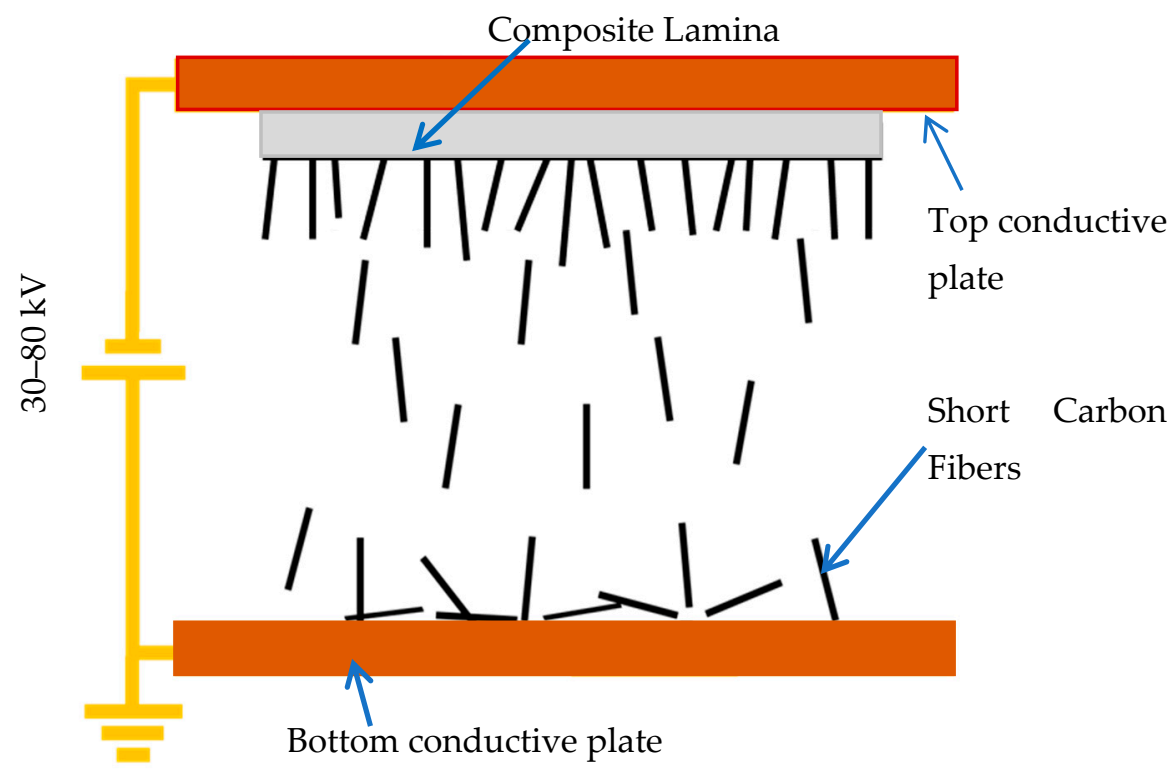

Figure 1. Schematic of wet electro-flocking method.

\subsection{Composite Fabrication Using Vacuum Infusion}

A standard vacuum infusion process $[20,21]$ was employed to fabricate composites where carbon fiber flocked laminates were first stacked in the vacuum bag. Two vacuum tubes were connected on each end of the vacuum bag. One tube was attached with a vacuum pump for the resin outlet, and the other tube was connected to a resin bucket for the resin inlet. The whole vacuum system was thoroughly sealed using the double-side gum tape. The epoxy mix with CNTs (CNTs and $\mathrm{Fe}_{3} \mathrm{O}_{4}$ nano particles) prepared in the Section 2.2 was infused into the vacuum bag through the resin inlet with a vacuum pump. During the infusion process, the original orientation of flocked fibers changed, and this could not be avoided. The infused composite was left at room temperature for 48 hours and later specimens of the required dimensions ( $12.7 \mathrm{~mm}$ width $\times 24.5 \mathrm{~mm}$ height $\times 2.5 \mathrm{~mm}$ thickness) were cut.

\subsection{Electromagnetic Shielding Effectiveness Measurements}

The total shielding effectiveness (SE), and that of absorption and reflection were measured using the set up shown in Figure 2. The set up consisted of a vector network analyzer (VNA-8510C), two standard WR-90 coaxial launchers to guide EM wave, and a copper sample holder in between the launchers. The wave guide launchers used in this study were in the frequency range of 8-12 GHz. The composite samples were fitted in the opening of the sample holder. The sample holder is bolted between the launchers. The incident EM wave had a power of $10 \mathrm{~dB}$. After calibration of the set-up, the wave transmittance loss in $\mathrm{dB}$ for conditions of no sample and with sample were collected from VNA and later subtracted to determine the total shielding effectiveness (SE) and those of absorption and reflection. VNA provides the $S$ parameters $\left\{S_{11}, S_{22}, S_{12}\right.$, and $\left.S_{21}\right\}$ in the frequency range 8-12 GHz. The measurements of $S$ parameters were provided in an incremental frequency of $0.4 \mathrm{GHz}$ within the above frequency range. $S_{11}$ or $S_{22}$ represents a reflection coefficient and $S_{12}$ or $S_{21}$ represents a transmission coefficient of the EM wave. The total SE, SE due to reflection, and SE due to absorption are expressed in terms of $\mathrm{S}$ parameters as below:

$$
\text { Total SE }=-10 \log _{10}\left(\left|\mathrm{~S}_{12}\right|^{2}\right) \mathrm{dB}
$$

SE due to Reflection (SER) $=-10 \log _{10}\left(1-\left|\mathrm{S}_{11}\right|^{2}\right) \mathrm{dB}$

$$
\text { SE due to Absorption (SEA) }=-10 \log _{10}\left(\left|S_{12}\right|^{2} /\left(1-\left|S_{11}\right|^{2}\right)\right) \mathrm{dB}
$$




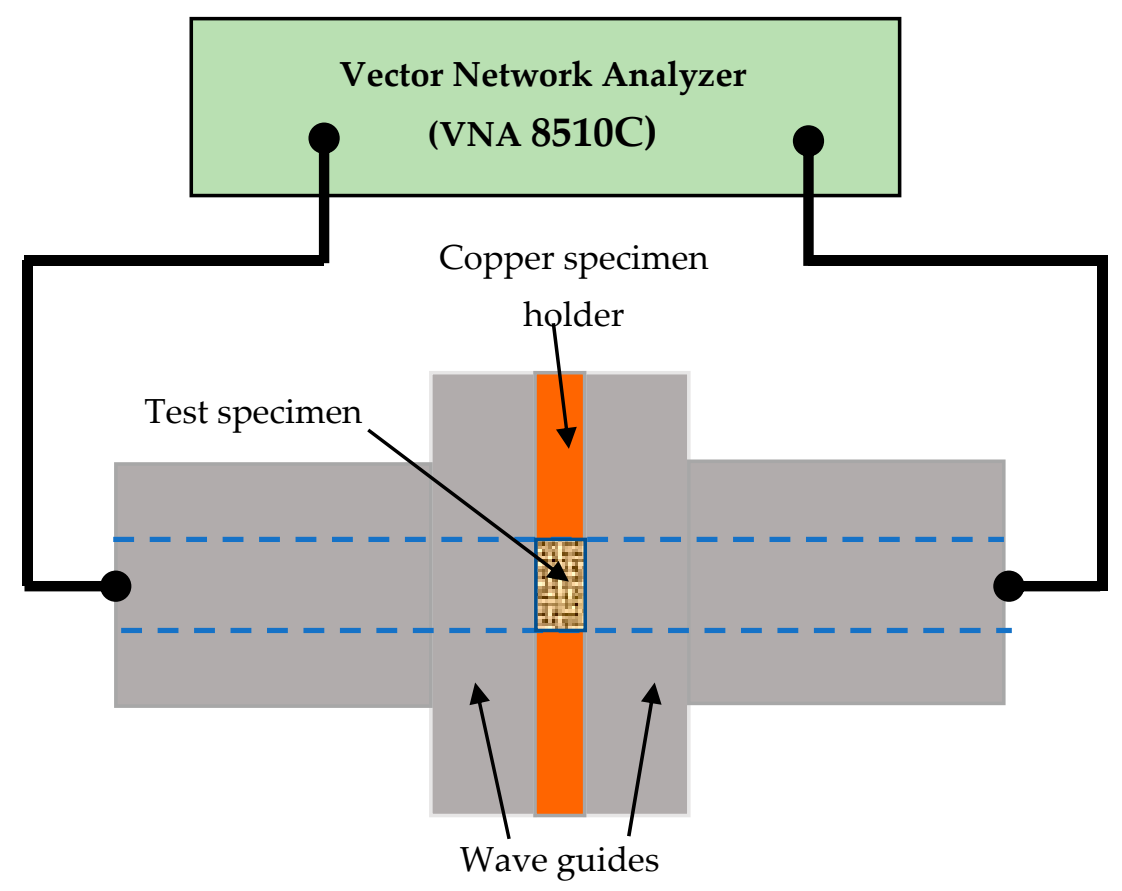

Figure 2. Schematic illustrating the method for measuring electromagnetic wave shielding effectiveness.

\section{Results and Discussion}

\subsection{Composites with $\mathrm{No} \mathrm{Fe}_{3} \mathrm{O}_{4}$ Nano Particles}

Figure 3 shows the EMS effectiveness results of (a) total $\mathrm{SE}$, (b) absorption $\mathrm{SE}\left(\mathrm{SE}_{\mathrm{A}}\right)$, and (c) reflection $\mathrm{SE}\left(\mathrm{SE}_{\mathrm{R}}\right)$ for composites having carbon fibers of fiber density of 1000 fibers $/ \mathrm{mm}^{2}$ and 2000 fibers $/ \mathrm{mm}^{2}$ of all three carbon fiber lengths without $\mathrm{Fe}_{3} \mathrm{O}_{4}$ nano particles. Total SE, $\mathrm{SE}_{\mathrm{A}}$, and $\mathrm{SE}_{\mathrm{R}}$ demonstrated higher values as the carbon fiber length increases from $80 \mu \mathrm{m}$ to $350 \mu \mathrm{m}$. A maximum value of $22 \mathrm{~dB}$ of total SE is observed at $8.4 \mathrm{GHz}$ for composites of $350 \mu \mathrm{m}$ carbon fiber with 1000 fibers $/ \mathrm{mm}^{2}$. However, at the same frequency, a maximum value of $14 \mathrm{~dB}$ is noted for composites of $80 \mu \mathrm{m}$ carbon fiber with 1000 fibers $/ \mathrm{mm}^{2}$. For $\mathrm{SE}_{\mathrm{A}}$, composites of $350 \mu \mathrm{m}$ carbon fiber with 1000 fibers $/ \mathrm{mm}^{2}$ had a maximum value of $15.6 \mathrm{~dB}$ at the frequency of $8.4 \mathrm{GHz}$. However, composites of $80 \mu \mathrm{m}$ carbon fiber with 1000 fibers $/ \mathrm{mm}^{2}$ has a maximum value of $9.81 \mathrm{~dB}$ at the frequency of $8.4 \mathrm{GHz}$.

It was well reported in the literature that the dielectric property of CNTs and carbon fibers provide improved attenuation of electromagnetic wave when they are reinforced in polymers [22,23]. Moreover, as the carbon fiber length increases, the electrical conductivity of the composite increases significantly as reported in our previous study [17]. The longer carbon fibers penetrate through the laminates during the stacking and vacuum infusion process and thus connect with CNTs in the epoxy of the laminates as well as with carbon fibers in neighboring laminates. Both leakage and tunneling currents increase due to the increased number of physical contacts and the smaller mean distance between the carbon fibers and CNTs. Leakage current regularly has more influence on conductivity than the tunneling current [24]. As it is evident from the Figure 3b, the total SE values have a major contribution from $\mathrm{SE}_{\mathrm{A}}$. Since $\mathrm{SE}_{\mathrm{A}}$ is proportional to electrical conductivity of the composite, the former increases with carbon fiber length.

$\mathrm{SE}$, due to reflection, is not a major contributor for total SE, for example, composites of $350 \mu \mathrm{m}$ carbon fiber length with 1000 fibers $/ \mathrm{mm}^{2}$ at $8.4 \mathrm{GHz}$, is only $29 \%$ of the total SE where the rest is from absorption. The values of $\mathrm{SE}_{\mathrm{R}}$ are lower for composites of shorter carbon fiber length $(80 \mu \mathrm{m})$ for most of the frequencies because of their lower electrical conductivity. $\mathrm{SE}_{\mathrm{R}}$ is proportional to conductivity and hence it is expected to have the trend shown in Figure 3c. 

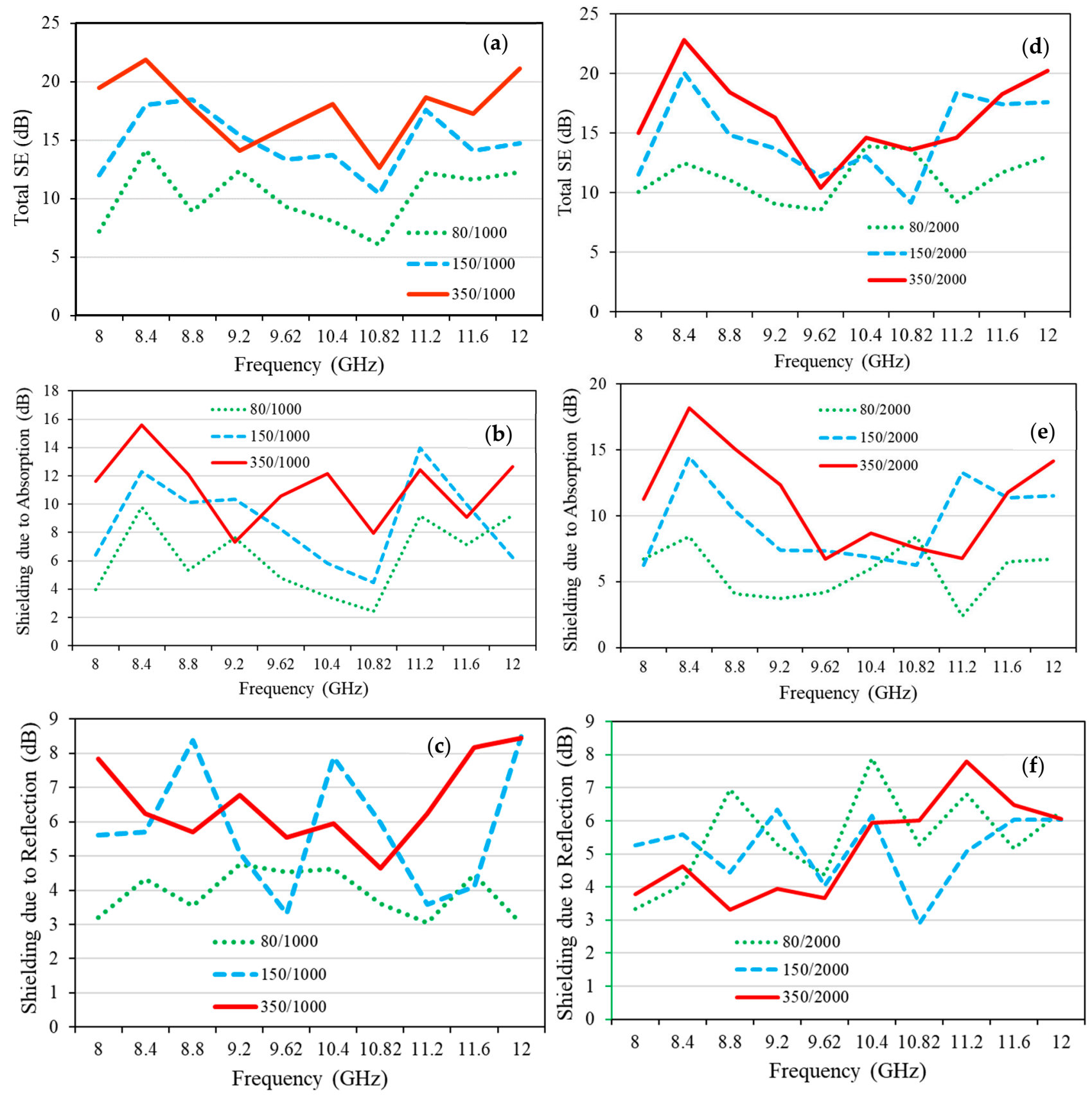

Figure 3. Shielding effectiveness of composites with no $\mathrm{Fe}_{3} \mathrm{O}_{4}$ nano particles and carbon fibers with fiber density of 1000 fibers $/ \mathrm{mm}^{2}$ (a) total SE, (b) absorption SE, and (c) reflection SE; carbon fibers with fiber density of 2000 fibers $/ \mathrm{mm}{ }^{2}$ (d) total SE, (e) absorption SE, and (f) reflection SE.

When comparison is made between two fiber densities of 1000 fibers $/ \mathrm{mm}^{2}$ and 2000 fibers $/ \mathrm{mm}^{2}$, the total $\mathrm{SE}, \mathrm{SE}_{\mathrm{A}}$, and $\mathrm{SE}_{\mathrm{R}}$ are slightly higher at certain frequencies for composites of 2000 fibers $/ \mathrm{mm}^{2}$ compared to 1000 fibers $/ \mathrm{mm}^{2}$ as shown in Figure 3d-f. A maximum total SE value of $23 \mathrm{~dB}$ is observed at $8.4 \mathrm{GHz}$ for composites of $350 \mu \mathrm{m}$ carbon fiber length with 2000 fibers $/ \mathrm{mm}^{2}$, which is only a $5 \%$ increase compared to composites of same length with 1000 fibers $/ \mathrm{mm}^{2}$. In our previous study, as the carbon fiber density increased from 1000 fibers $/ \mathrm{mm}^{2}$ to 2000 fibers $/ \mathrm{mm}^{2}$, composites conductivity increased by 10 times for all carbon fiber lengths [16]. It is expected to see significant increases in both total $\mathrm{SE}$ and $\mathrm{SE}_{\mathrm{A}}$, however the fiber density surprisingly did not make the impact on the measurements. However, for $\mathrm{SE}_{\mathrm{R}}$, composites of $80 \mu \mathrm{m}$ carbon fiber length at fiber density of 2000 fibers $/ \mathrm{mm}^{2}$ showed significant improvement of $70 \%$ when compared to that of 
1000 fibers $/ \mathrm{mm}^{2}$. The increase in fiber density from 1000 fibers $/ \mathrm{mm}^{2}$ to 2000 fibers $/ \mathrm{mm}^{2}$ could have compensated the shortcomings of fiber length and improved the electrical conductivity of the composite.

\subsection{Composites with $\mathrm{Fe}_{3} \mathrm{O}_{4}$ Nano Particles of $0.5 \mathrm{wt} \%$}

Shielding effectiveness of composites having $\mathrm{Fe}_{3} \mathrm{O}_{4}$ nano particles with all carbon fiber lengths and both fiber densities is shown in Figure 4. The addition of $\mathrm{Fe}_{3} \mathrm{O}_{4}$ nano particles improved both the total SE and $\mathrm{SE}_{\mathrm{A}}$ almost twofold when compared with composites having no $\mathrm{Fe}_{3} \mathrm{O}_{4}$ nano particles, as shown in Figure 3. The combined effect of dielectric loss due to presence of CNTs and carbon fiber; and magnetic losses due to presence of $\mathrm{Fe}_{3} \mathrm{O}_{4}$ nano particles is clearly evident for the improvement of the total SE and $\mathrm{SE}_{\mathrm{A}}$, as shown in Figure 4. The addition of $\mathrm{Fe}_{3} \mathrm{O}_{4}$ nano particles enhances interfacial polarization between the particles and the surface polarization of the particles, which improves shielding effectiveness $[25,26]$. Furthermore, the particle size of $\mathrm{Fe}_{3} \mathrm{O}_{4}$ takes a very important role for the enhancement of total SE. The $\mathrm{Fe}_{3} \mathrm{O}_{4}$ nanoparticles used in this study have the size of $20 \mathrm{~nm}$ (>99.5\% pure). For this size range, the orientation of the spins in each domain gets modified themselves and this contributes to the improvement of magnetization [27]. The surface to volume ratio is also high for this size range of nanoparticles which also contributes to the increase of magnetization. The composites of $350 \mu \mathrm{m}$ carbon fiber length with 1000 fibers $/ \mathrm{mm}^{2}$ demonstrates a maximum total SE value of $41 \mathrm{~dB}$ at $8.8 \mathrm{GHz}$ as shown in Figure 4 a. This value is about $86 \%$ higher than that of same composites with no $\mathrm{Fe}_{3} \mathrm{O}_{4}$ nano particles. On the other hand, composites of $80 \mu \mathrm{m}$ carbon fiber length with 1000 fibers $/ \mathrm{mm}^{2}$, showed maximum values of $14.4 \mathrm{~dB}$ at frequency of $12 \mathrm{GHz}$. This value is about $15 \%$ higher than that of no $\mathrm{Fe}_{3} \mathrm{O}_{4}$ nano particles shown in Figure 3a. The combined effect of higher electrical conductivity due to longer carbon fibers; and improved magnetic permeability due to addition of $\mathrm{Fe}_{3} \mathrm{O}_{4}$ nano particles increases the total SE value significantly for composites of carbon fiber density of 1000 fibers $/ \mathrm{mm}^{2}$. It is reported in the literature that the catalyst growth of crystalline graphite during carbonization process can be enhanced by adding $\mathrm{Fe}_{3} \mathrm{O}_{4}$ nano particles which might have further improved the composite's conductivity [28].

Like composites with no $\mathrm{Fe}_{3} \mathrm{O}_{4}$ nano particles, the contribution of $\mathrm{SE}_{\mathrm{A}}$ to the total $\mathrm{SE}$ value is significant for composites with $\mathrm{Fe}_{3} \mathrm{O}_{4}$ nano particles as shown in Figure $4 \mathrm{~b}$. A maximum value of $37 \mathrm{~dB}$ is noticed for composites of $350 \mu \mathrm{m}$ carbon fiber length with 1000 fibers $/ \mathrm{mm}^{2}$ at a frequency of $8.8 \mathrm{GHz}$. This is about $84 \%$ of the total SE value for this composite type at the same frequency of $8.8 \mathrm{GHz}$. For the same composite type, $\mathrm{SE}_{\mathrm{A}}$ with $\mathrm{Fe}_{3} \mathrm{O}_{4}$ nano particles is 3 times higher than that of no $\mathrm{Fe}_{3} \mathrm{O}_{4}$ nano particles at frequency of 8.8 GHz. Since $\mathrm{SE}_{\mathrm{A}}$ is proportional to both conductivity and permeability of composite, the reported values follow the expected trend with the addition of $\mathrm{Fe}_{3} \mathrm{O}_{4}$ nano particles. However, the addition of $\mathrm{Fe}_{3} \mathrm{O}_{4}$ nano particles did not improve the $\mathrm{SE}_{\mathrm{A}}$ for composites of $80 \mu \mathrm{m}$ carbon fiber length with 1000 fibers $/ \mathrm{mm}^{2}$ when compared to other two carbon fiber length cases. For these composite types with $\mathrm{Fe}_{3} \mathrm{O}_{4}$ nano particles, about $20 \%$ improvement of $\mathrm{SE}_{\mathrm{A}}$ is observed when compared to that of no $\mathrm{Fe}_{3} \mathrm{O}_{4}$ nano particles at the frequency of $12 \mathrm{GHz}$ shown in Figure 3b.

For $\mathrm{SE}_{\mathrm{R}}$, the addition of the $\mathrm{Fe}_{3} \mathrm{O}_{4}$ nano particles reduced the values of composites considerably, as shown in Figure $4 c$, when compared to those with no $\mathrm{Fe}_{3} \mathrm{O}_{4}$ nano particles, shown in Figure 3c. For example, the value of $S_{R}$ decreased by $25 \%$ with the addition of $\mathrm{Fe}_{3} \mathrm{O}_{4}$ nano particles for composites of $350 \mu \mathrm{m}$ carbon fiber length with 1000 fibers $/ \mathrm{mm}^{2}$ at the frequency of $12 \mathrm{GHz}$. This is expected as the $\mathrm{SE}_{\mathrm{R}}$ values are inversely proportional to magnetic permeability [29]. The addition of $\mathrm{Fe}_{3} \mathrm{O}_{4}$ nano particles increases the permeability values as reported in the literature $[25,26]$. The decrease of SE value due to reflection is much lower for composites of $80 \mu \mathrm{m}$ carbon fiber length with 1000 fibers $/ \mathrm{mm}^{2}$, where the value reduced by $97 \%$ with addition of $\mathrm{Fe}_{3} \mathrm{O}_{4}$ nano particles for the frequency value of $9.2 \mathrm{GHz}$. 

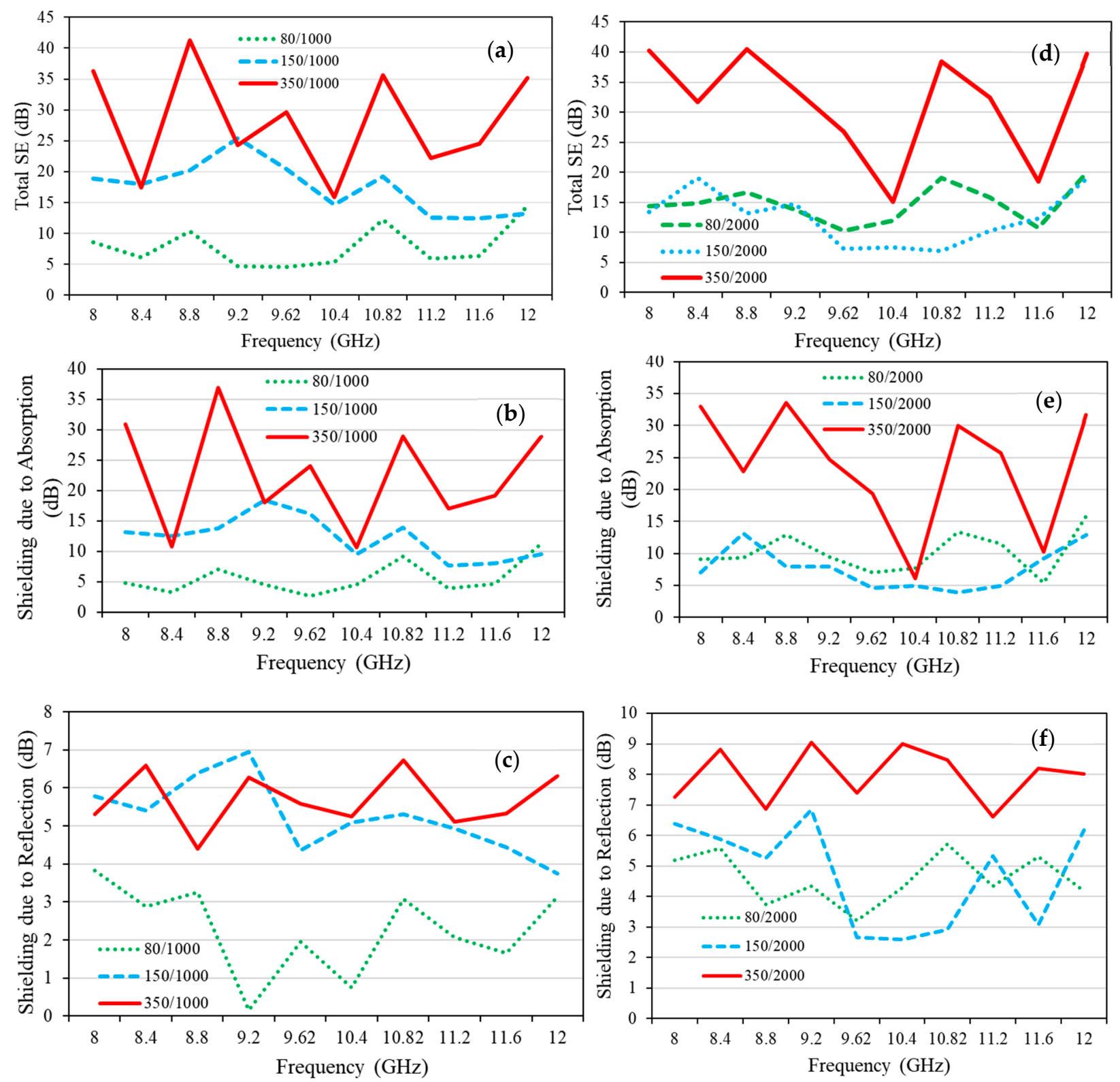

Figure 4. Shielding effectiveness of composites with $\mathrm{Fe}_{3} \mathrm{O}_{4}$ nano particles of $0.5 \mathrm{wt}$. $\%$ and carbon fibers with fiber density of 1000 fibers $/ \mathrm{mm}^{2}$ (a) total SE, (b) absorption SE, and (c) reflection SE; carbon fibers with fiber density of 2000 fibers $/ \mathrm{mm}^{2}$ (d) total SE, (e) absorption SE, and (f) reflection SE.

The fiber density once again did not demonstrate significant influence on total SE and $\mathrm{SE}$ due to absorption even with the addition of $\mathrm{Fe}_{3} \mathrm{O}_{4}$ nano particles similar to composites with no $\mathrm{Fe}_{3} \mathrm{O}_{4}$ nano particles. However, it again played some improvement in $\mathrm{SE}_{\mathrm{R}}$ at higher fiber density of 2000 fibers $/ \mathrm{mm}^{2}$. For composites of $350 \mu \mathrm{m}$ carbon fiber length, an increase of $47 \%$ of $\mathrm{SE}_{\mathrm{R}}$ at $9.2 \mathrm{GHz}$ is noticed when the fiber density increased from 1000 fibers $/ \mathrm{mm}^{2}$ to 2000 fibers $/ \mathrm{mm}^{2}$. The improvement is 27 times for composite of $80 \mu \mathrm{m}$ carbon fiber length at the same frequency of $9.2 \mathrm{GHz}$ when the fiber density increased from 1000 fibers $/ \mathrm{mm}^{2}$ to 2000 fibers $/ \mathrm{mm}^{2}$. This once again reinforces the fact that higher density of 2000 fibers $/ \mathrm{mm}^{2}$ compensates for the shortcoming of being shorter a carbon fiber length of $80 \mu \mathrm{m}$.

\subsection{Composites with $\mathrm{Fe}_{3} \mathrm{O}_{4}$ Nano Particles of 1.0 wt.\%}

Figure 5 shows the total $\mathrm{SE}, \mathrm{SE}_{\mathrm{A}}$, and $\mathrm{SE}_{\mathrm{R}}$ for composites with $\mathrm{Fe}_{3} \mathrm{O}_{4}$ nano particles of $1.0 \mathrm{wt} . \%$ and at two different fiber densities. The addition of $1.0 \mathrm{wt} . \%$ of $\mathrm{Fe}_{3} \mathrm{O}_{4}$ nano 
particles almost increased the total $\mathrm{SE}$ and $\mathrm{SE}_{\mathrm{A}}$ values of all composites of fiber density of 1000 fibers $/ \mathrm{mm}^{2}$ by two times when compared to those of $0.5 \mathrm{wt} . \%$ of $\mathrm{Fe}_{3} \mathrm{O}_{4}$ nano particles. For example, composites of carbon fiber length of $350 \mu \mathrm{m}$ with fiber density of 1000 fibers $/ \mathrm{mm}^{2}$ showed $125 \%$ improvement in total $\mathrm{SE}$ value at $1.0 \mathrm{wt} . \%$ of $\mathrm{Fe}_{3} \mathrm{O}_{4}$ nano particles compared to that of composites with $0.5 \mathrm{wt} . \%$ of $\mathrm{Fe}_{3} \mathrm{O}_{4}$ nano particles at a frequency of $8 \mathrm{GHz}$. This improvement is primarily due to the improvement in magnetic permeability of the composite. Moreover, the extra amount of $\mathrm{Fe}_{3} \mathrm{O}_{4}$ nano particles enhanced both the interfacial polarization between the particles and the surface polarization of the particles. The increase in total SE value is more pronounced for composites of carbon fiber length of $80 \mu \mathrm{m}$ with fiber density of 1000 fibers $/ \mathrm{mm}^{2}$, where an improvement of $155 \%$ is noticed at $1.0 \mathrm{wt} . \%$ of $\mathrm{Fe}_{3} \mathrm{O}_{4}$ nano particles compared to composites with $0.5 \mathrm{wt} . \%$ of $\mathrm{Fe}_{3} \mathrm{O}_{4}$ nano particles at the frequency of $8.4 \mathrm{GHz}$.
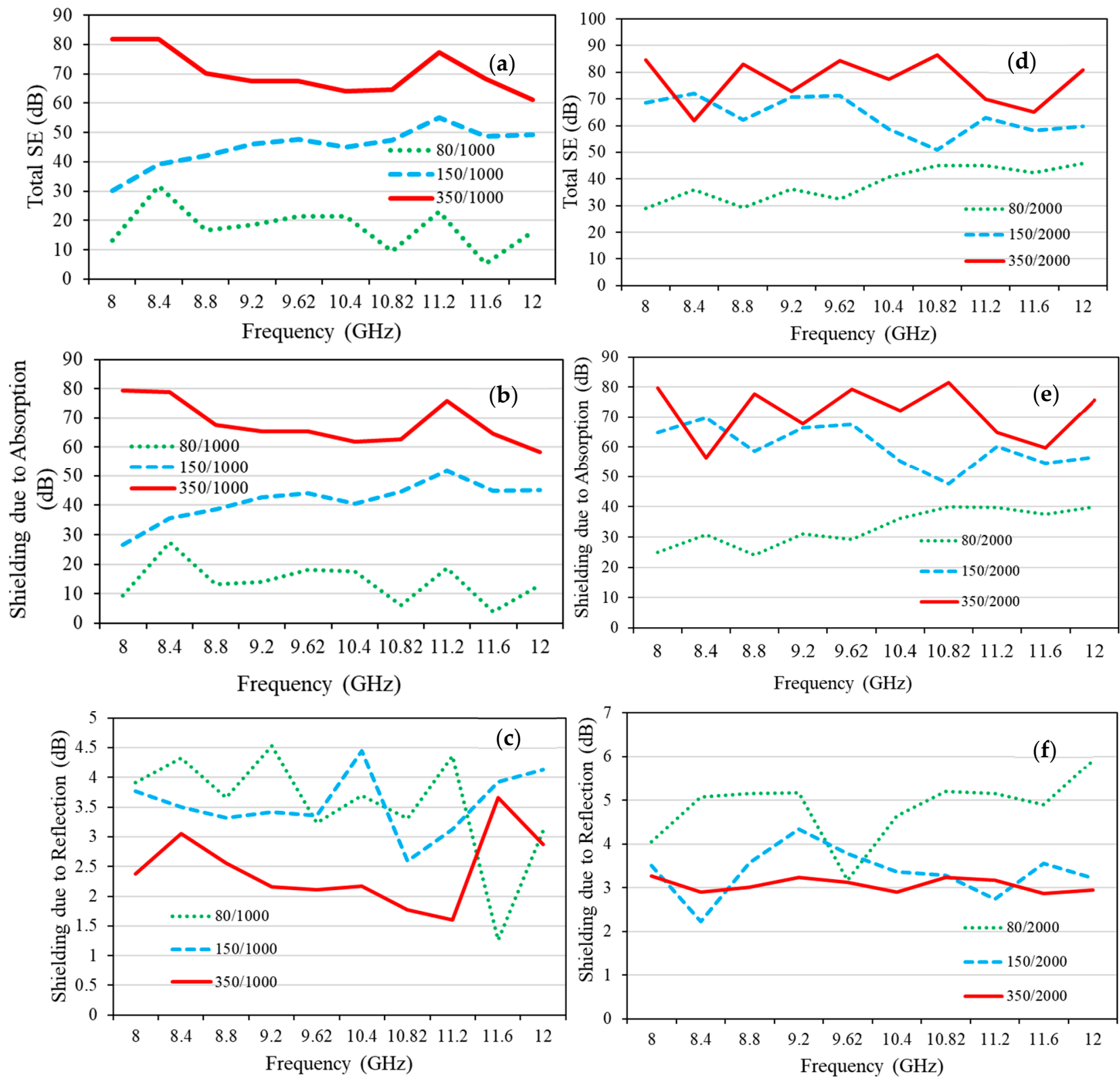

Figure 5. Shielding effectiveness of composites with $\mathrm{Fe}_{3} \mathrm{O}_{4}$ nano particles of $1.0 \mathrm{wt} . \%$ and carbon fibers with fiber density of 1000 fibers $/ \mathrm{mm}^{2}$ (a) total SE, (b) absorption SE, and (c) reflection SE; carbon fibers with fiber density of 2000 fibers $/ \mathrm{mm}{ }^{2}$ (d) total SE, (e) absorption SE, and (f) reflection SE. 
Like previous composite types, the $\mathrm{SE}_{\mathrm{A}}$ is a major contributor of the total $\mathrm{SE}$ value. For composites with a fiber density of 1000 fibers $/ \mathrm{mm}^{2}$ at $1.0 \mathrm{wt} . \%$ of $\mathrm{Fe}_{3} \mathrm{O}_{4}$ nano particles, $\mathrm{SE}_{\mathrm{A}}$ contributes almost $97 \%$ of the total SE value. This composite scenario is the best case for several defense related applications where SE due to absorption is a major requirement of electromagnetic shielding. When comparison is made to check the impact of a higher amount of $\mathrm{Fe}_{3} \mathrm{O}_{4}$ nano particles on SE value due to absorption, composites of carbon length of $350 \mu \mathrm{m}$ with fiber density of 1000 fibers $/ \mathrm{mm}^{2}$ showed $156 \%$ improvement at $1.0 \mathrm{wt} . \%$ of $\mathrm{Fe}_{3} \mathrm{O}_{4}$ nano particles compared to that of composites with $0.5 \mathrm{wt} . \%$ of $\mathrm{Fe}_{3} \mathrm{O}_{4}$ nano particles at the frequency of $8 \mathrm{GHz}$. An improved situation of $\mathrm{SE}_{\mathrm{A}}$ is observed for composites of shorter carbon length of $80 \mu \mathrm{m}$ with fiber density of $1000 \mathrm{fibers} / \mathrm{mm}^{2}$, where an improvement of $195 \%$ is noticed at $1.0 \mathrm{wt} . \%$ of $\mathrm{Fe}_{3} \mathrm{O}_{4}$ nano particles compared to that of composites with $0.5 \mathrm{wt} . \%$ of $\mathrm{Fe}_{3} \mathrm{O}_{4}$ nano particles at the frequency of $8 \mathrm{GHz}$. When compared to case of composites of $0.5 \mathrm{wt} . \%$ of $\mathrm{Fe}_{3} \mathrm{O}_{4}$ nano particles (Figure $4 \mathrm{~b}$ ) against the composites with no $\mathrm{Fe}_{3} \mathrm{O}_{4}$ nano particles (Figure 3b), the additional amount of $1.0 \mathrm{wt} . \%$ of $\mathrm{Fe}_{3} \mathrm{O}_{4}$ nano particles (Figure $5 \mathrm{~b}$ ) against the composites of $0.5 \mathrm{wt} . \%$ of $\mathrm{Fe}_{3} \mathrm{O}_{4}$ nano particles (Figure $4 \mathrm{~b}$ ) showed much higher improvement in total $\mathrm{SE}$ values and $\mathrm{SE}_{\mathrm{A}}$ values.

With the increase of $\mathrm{Fe}_{3} \mathrm{O}_{4}$ nano particles to $1.0 \mathrm{wt} . \%$, the $\mathrm{SE}_{\mathrm{R}}$ for composites of fiber density of 1000 fibers $/ \mathrm{mm}^{2}$ reduces significantly when compared to those of $0.5 \mathrm{wt} . \%$ of $\mathrm{Fe}_{3} \mathrm{O}_{4}$ nano particles for both carbon fiber lengths of $150 \mu \mathrm{m}$ and $350 \mu \mathrm{m}$. The presence of more $\mathrm{Fe}_{3} \mathrm{O}_{4}$ nano particles further increases the magnetic permeability, which in turn reduces the $\mathrm{SE}_{\mathrm{R}}$ as expected. For example, composites of carbon fiber length of $350 \mu \mathrm{m}$ with fiber density of 1000 fibers $/ \mathrm{mm}^{2}$ showed a reduction of $280 \%$ in $\mathrm{SE}_{\mathrm{R}}$ compared to those of $0.5 \mathrm{wt} . \%$ of $\mathrm{Fe}_{3} \mathrm{O}_{4}$ nano particles at the frequency of $10.82 \mathrm{GHz}$. However, for composites of carbon fiber length of $80 \mu \mathrm{m}$ with fiber density of 1000 fibers $/ \mathrm{mm}^{2}$ showed $213 \%$ increase in $\mathrm{SE}_{\mathrm{R}}$ at $1.0 \mathrm{wt} . \%$ of $\mathrm{Fe}_{3} \mathrm{O}_{4}$ nano particles compared to those of $0.5 \mathrm{wt} . \%$ of $\mathrm{Fe}_{3} \mathrm{O}_{4}$ nano particles at the frequency of $9.2 \mathrm{GHz}$. The reasons for such increase at this frequency are not clear and needs further investigation.

At the higher fiber density of 2000 fibers $/ \mathrm{mm}^{2}$, composites of carbon fiber lengths of both $80 \mu \mathrm{m}$ and $150 \mu \mathrm{m}$ showed improvements in total SE values and $\mathrm{SE}_{\mathrm{A}}$ when compared to those of 1000 fibers $/ \mathrm{mm}^{2}$. The higher fiber density of carbon fibers demonstrates its impact in the presence of $1.0 \mathrm{wt} . \%$ of $\mathrm{Fe}_{3} \mathrm{O}_{4}$ nano particles to improve the shielding effectiveness by enhancing the interfacial polarization between the particles and the surface polarization of the particles. For example, composites of carbon fiber length of $150 \mu \mathrm{m}$ at fiber density of 2000 fibers $/ \mathrm{mm}^{2}$, showed a $50 \%$ improvement in total SE value compared to that of fiber density of 1000 fibers $/ \mathrm{mm}^{2}$ at the frequency of $9.62 \mathrm{GHz}$. In the case of composites of carbon fiber length of $80 \mu \mathrm{m}$, a higher percentage of improvement of $185 \%$ was noticed for total SE value at the fiber density of 2000 fibers $/ \mathrm{mm}^{2}$ compared to those of fiber density of 1000 fibers $/ \mathrm{mm}^{2}$ at the frequency of $12 \mathrm{GHz}$. Composites of carbon fiber length of $350 \mu \mathrm{m}$ and fiber density of 2000 fibers $/ \mathrm{mm}^{2}$ along with $1.0 \mathrm{wt} . \%$ of $\mathrm{Fe}_{3} \mathrm{O}_{4}$ nano particles showed the highest total $\mathrm{SE}$ and $\mathrm{SE}_{\mathrm{A}}$ values compared to all composite types. The longer carbon fibers penetrate the neighboring glass laminates thus providing higher electrical conductivity as found in our previous study [17]. The higher amount of $1.0 \mathrm{wt} . \%$ of $\mathrm{Fe}_{3} \mathrm{O}_{4}$ nano particles provides greater magnetic permeability as reported in the literature [24,25]. Hence the synergetic effect of carbon fibers and $\mathrm{Fe}_{3} \mathrm{O}_{4}$ nano particles resulted in the highest total $\mathrm{SE}$ and $\mathrm{SE}_{\mathrm{A}}$ values for this composite type. The increase of carbon fiber density from 1000 to 2000 fibers $/ \mathrm{mm}^{2}$ has no significant impact on the $\mathrm{SE}_{\mathrm{R}}$.

\section{Conclusions}

An experimental characterization was performed to investigate the effect of carbon nanotubes, micro carbon fibers, and $\mathrm{Fe}_{3} \mathrm{O}_{4}$ nano particles on electromagnetic shielding effectiveness in the $\mathrm{X}$-band frequency range (8-12 GHz). Overall, the $\mathrm{Fe}_{3} \mathrm{O}_{4}$ nano particles have a major influence on the total shielding effectiveness as well as on the absorption. The major outcomes of this study are:

- $\mathrm{SE}$ value of absorption is a major contributor for the total SE value for all composite types. 
- Carbon fibers ( $350 \mu \mathrm{m}$ long fibers, the fiber density of 2000 fibers $\left./ \mathrm{mm}^{2}\right)$ and $\mathrm{Fe}_{3} \mathrm{O}_{4}$ nano particles (1.0 wt.\%) provided the highest total SE and $\mathrm{SE}_{\mathrm{A}}$.

- The increase of fiber density of carbon fibers from 1000 to 2000 fibers $/ \mathrm{mm}^{2}$ did not have considerable impact on total SE and SE value due to absorption in composites with no $\mathrm{Fe}_{3} \mathrm{O}_{4}$ nano particles and with $0.5 \mathrm{wt} . \%$ of $\mathrm{Fe}_{3} \mathrm{O}_{4}$ nano particles.

- At $1.0 \mathrm{wt} . \%$ of $\mathrm{Fe}_{3} \mathrm{O}_{4}$ nano particles, and at a higher fiber density of 2000 fibers $/ \mathrm{mm}^{2}$, composites of carbon fiber lengths of both $80 \mu \mathrm{m}$ and $150 \mu \mathrm{m}$ showed significant improvements of total SE values and SE values due to absorption when compared to those of 1000 fibers $/ \mathrm{mm}^{2}$.

Author Contributions: N.Y.: Fabrication, Experiments, Data analysis; V.C.: Supervision; Project administration, Writing-original draft preparation. All authors have read and agreed to the published version of the manuscript.

Funding: This research received no external funding.

Institutional Review Board Statement: Not applicable.

Informed Consent Statement: Not applicable.

Data Availability Statement: The datasets generated during and/or analyzed during the current study are available from the corresponding author on reasonable request.

Acknowledgments: Authors sincerely thank Yefei Li at UMass Dartmouth for giving access to use vector network analyzer for shielding effectiveness measurements.

Conflicts of Interest: The authors have no conflicts of interest to declare that are relevant to the content of this article.

\section{References}

1. Norman, R.H. Conducting Rubbers and Plastics; Elsevier: Oxford, UK, 1970.

2. Wang, Y.; Jing, X. Intrinsically conducting polymers for electromagnetic interference shielding. Polym. Adv. Technol. 2005, 16, 344-351. [CrossRef]

3. Faez, R.; Schuster, R.H.; De Paoli, M.A. A conductive elastomer based on EPDM and polyaniline 2. Effect of the crosslinking method. Eur. Polym. J. 2002, 38, 2459-2463. [CrossRef]

4. Fox, R.T.; Wani, V.; Howard, K.E.; Bogle, A.; Kempel, L. Conductive polymer composite materials and their utility in electromagnetic shielding applications. J. Appl. Polym. Sci. 2008, 107, 2558-2566. [CrossRef]

5. Jou, W.-S.; Cheng, H.-Z.; Hsu, C.-F. The electromagnetic shielding effectiveness of carbon nanotubes polymer composites. J. Alloy. Compd. 2007, 434-435, 641-645. [CrossRef]

6. Park, S.-H.; Thelimann, P.T.; Asbeck, P.M.; Bandaru, P.R. Enhanced Electromagnetic Interference Shielding Through the Use of Functionalized Carbon-Nanotube-Reactive Polymer Composites. IEEE Trans. Nanotechnol. 2009, 9, 464-469. [CrossRef]

7. Jalali, M.; Dauterstedt, S.; Michaud, A.; Wuthrich, R. Electromagnetic shielding of polymer-matrix composites with metallic nanoparticles. Compos. Part B Eng. 2011, 42, 1420-1426. [CrossRef]

8. Joshi, A.; Bajaj, A.; Singh, R.; Anand, A.; Alegaonkar, P.S.; Datar, S. Processing of graphene nanoribbon based hybrid composite for electromagnetic shielding. Compos. Part B Eng. 2015, 69, 472-477. [CrossRef]

9. Jia, Y.; Li, K.; Xue, L.; Ren, J.; Zhang, S.; Li, H. Mechanical and electromagnetic shielding performance of carbon fiber reinforced multilayered (PyC-SiC)n matrix composites. Carbon 2017, 111, 299-308. [CrossRef]

10. Saini, P.; Choudhary, V. Enhanced electromagnetic interference shielding effectiveness of polyaniline functionalized carbon nanotubes filled polystyrene composites. J. Nanopart. Res. 2013, 15, 1415. [CrossRef]

11. Hu, W.; Zhang, J.; Liu, B.; Zhang, C.; Zhao, Q.; Sun, Z.; Cao, H.; Zhu, G. Synergism between lignin, functionalized carbon nanotubes and $\mathrm{Fe} 3 \mathrm{O} 4$ nanoparticles for electromagnetic shielding effectiveness of tough lignin-based polyurethane. Compos. Commun. 2021, 24, 100616. [CrossRef]

12. Shuba, M.V.; Yuko, D.; Kuzhir, P.P.; Maksimenko, S.A.; Ksenevich, V.K.; Lim, S.-H.L.; Kim, T.-H.; Choi, S.-M. Electromagnetic and optical responses of a composite material comprising individual single-walled carbon-nanotubes with a polymer coating. Sci. Rep. 2020, 10, 9361. [CrossRef]

13. Chen, H.C.; Lee, K.C.; Lin, J.H.; Koch, M. Fabrication of conductive woven fabric and analysis of electromagnetic shielding via measurement and empirical equation. J. Mater. Process. Tech. 2007, 184, 124-130. [CrossRef]

14. Huang, C.-H.; Lin, J.-H.; Yang, R.-B.; Lin, C.-W.; Lou, C.-W. Metal/PET Composite Knitted Fabrics and Composites: Structural Design and Electromagnetic Shielding Effectiveness. J. Electron. Mater. 2012, 41, 2267-2273. [CrossRef]

15. Tugirumubano, A.; Vijay, S.J.; Go, S.H.; Shin, H.J.; Ku, K.L.; Kim, H.G. The evaluation of electromagnetic shielding properties of CFRP/metal mesh hybrid woven laminated composites. J. Compos. Mater. 2018, 52, 3819-3829. [CrossRef] 
16. Rojas, J.A.; Ribeiro, B.; Rezende, M.C. Influence of serrated edge and rectangular strips of MWCNT buckypaper on the electromagnetic properties of glass fiber/epoxy resin composites. Carbon 2020, 160, 317-327. [CrossRef]

17. O’Donnell, J.; Chalivendra, V.; Hall, A.; Haile, M.; Nataraj, L.; Coatney, M.; Kim, Y. Electro-mechanical studies of multi-functional glass fiber/epoxy reinforced composites. J. Reinf. Plast. Compos. 2019, 38, 506-520. [CrossRef]

18. Yang, S.; Meninno, C.; Chalivendra, V.; Kim, Y. Electro-bending Behavior of Curved Natural Fiber Laminated Composites. Compos. Struct. 2020, 238, 112004. [CrossRef]

19. Kim, Y.K.; Lewis, A.F.; Rice, J.M. Materials Methodology to Improve the Delamination Strength of Laminar Composites. U.S. Patent 7,981,495, 19 July 2011.

20. Pinto, M.; Chalivendra, V.B.; Kim, Y.K.; Lewis, A.M. Evaluation of Surface Treatment and Fabrication Methods for Jute Fiber/Epoxy Laminar Composites. Polym. Compos. 2014, 35, 310-317. [CrossRef]

21. Yang, S.; Chalivendra, V.B.; Kim, Y.K. Fracture and impact characterization of novel auxetic Kevlar/Epoxy laminated composites. Compos. Struct. 2017, 168, 120-129. [CrossRef]

22. Gorgi, J.P.; Bhattacharya, N.S.; Bhattacharya, N.S. Single layer microwave absorber based on expanded graphite-novolac phenolic resin composite for Xband applications. Compos. Part B Eng. 2014, 58, 518-523.

23. Oh, J.-H.; Oh, K.-S.; Kim, C.-G.; Hong, C.-S. Design of radar absorbing structures using glass/epoxy composite containing carbon black in X-band frequency ranges. Compos. Part B Eng. 2004, 35, 49-56. [CrossRef]

24. Kashi, S.; Gupta, R.K.; Buau, T.; Kao, N.; Bhattacharya, S.N. Morphology, electromagnetic properties and electromagnetic interference shielding performance of poly lactide/graphene nanoplatelet nanocomposites. Mater. Des. 2016, 95, 119-126. [CrossRef]

25. Song, W.-L.; Guan, X.-T.; Fan, L.-Z.; Cao, W.-Q.; Wang, C.-Y.; Zhao, Q.-L.; Cao, M.-S. Magnetic and conductive graphene papers toward thin layers of effective electromagnetic shielding. J. Mater. Chem. A 2015, 3, 2097-2107. [CrossRef]

26. Bayat, M.; Yang, H.; Ko, F. Effect of iron oxide nanoparticle size on electromagnetic properties of composite nanofibers. J. Compos. Mater. 2017, 52, 1723-1736. [CrossRef]

27. Basith, M.A.; Yesmin, N.; Hossain, R. Low temperature synthesis of Bismuth Ferrite nanoparticles with enhanced magnetization and promising photocatalytic performance in dye degradation and hydrogen evolution. RSC Adv. 2018, 8, 29613. [CrossRef]

28. Kim, H.M.; Kim, K.; Lee, C.Y.; Joo, J.; Cho, S.J.; Yoon, H.S.; Pejakovic, D.A.; Yoo, J.W.; Epstein, A.J. Electrical conductivity and electromagnetic interference shielding of multiwalled carbon nanotube composites containing Fe catalyst. Appl. Phys. Lett. 2004, 84, 589-591. [CrossRef]

29. Shukla, V. Review of electromagnetic interference shielding materials fabricated by iron ingredients. Nanosc. Adv. 2019, 1, 1640-1671. [CrossRef] 